\title{
Ultrasonographic Evaluation of Uterine Involution in the Early Puerperium
}

\section{Avaliação ultrassonográfica da involução uterina no puerpério precoce}

\author{
Juliana Hocevar Kristoschek ${ }^{1}$ Renato Augusto Moreira de Sá ${ }^{1,2}$ Fernanda Campos da Silva ${ }^{3}$ \\ Guillermo Coca Vellarde ${ }^{1}$
}

${ }^{1}$ Medical Sciences Post Graduation, Universidade Federal Fluminense, Niterói, RJ, Brazil

${ }^{2}$ Clinical Research Unit, Instituto Fernandes Figueira, Fiocruz, Rio de Janeiro, RJ, Brazil

3 Universidade Federal do Estado do Rio de Janeiro (UNIRIO), Rio de Janeiro, RJ, Brazil

Rev Bras Ginecol Obstet 2017;39:149-154.

\begin{abstract}
Address for correspondence Renato Augusto Moreira de Sá, PhD, Unidade de Pesquisa Clínica - Av. Rui Barbosa 716, Flamengo, Rio de Janeiro, RJ, Brazil (e-mail: rsa@cpdt.com.br).
\end{abstract}

\begin{abstract}
Keywords

- postpartum period

- uterus

- ultrasonography

Purpose Our aim was to describe the changes observed by ultrasonography in uterine dimensions during the early puerperium among women who experienced an uncomplicated puerperium. Additionally, the influence of parity, mode of delivery, breastfeeding and birth weight on uterine involution was evaluated.

Methods Ninety-one patients underwent an ultrasound examination on days 1 (D1), 2 (D2) and 7 (D7) of the postpartum period. The longitudinal, anteroposterior and transverse uterine diameters were measured, and the uterine volume was calculated by the formula: longitudinal diameter (LD) $\mathrm{X}$ anteroposterior diameter (APD) $\mathrm{X}$ transverse diameter (TD) $\mathrm{X}$ 0.45 . The thickness and length of the uterine cavity were also measured.

Results The uterine volume and the LD, APD and TD decreased by $44.8 \%, 20.9 \%$, $11.8 \%$ and $20.0 \%$ respectively. The uterine cavity thickness was reduced by $23 \%$, and the length of the cavity was reduced by $27.2 \%$ on D7. Uterine involution was correlated inversely with parity when the day of the postpartum period was not taken into account $(p=0.01)$. However, when the uterine involution was correlated to parity separately, with D1, D2 or D3, no correlations were found. A significant difference occurred at D2, when it was found that the uterus had a smaller volume following cesarean section compared with vaginal delivery $(p=0.04)$. The high birth weight and breastfeeding were significantly related to uterine involution ( $p \leq 0.01$ and $p=0.04$ ).

Conclusion The sonographic evaluation of the uterus in the early puerperium should consider birth weight, breastfeeding and parity, as well as the delivery route on D2, to identify abnormalities related to uterine involution.
\end{abstract}

Resumo

Objetivo Descrever as alterações observadas pela ultrassonografia nas dimensões uterinas durante o puerpério precoce em mulheres com evolução puerperal não received

May 27, 2016 accepted after revision January 12, 2017 published online April 3, 2017
DOI http://dx.doi.org/ 10.1055/s-0037-1601418. ISSN $0100-7203$.
Copyright $\odot 2017$ by Thieme-Revinter

Publicações Ltda, Rio de Janeiro, Brazil
License terms

(요 (1) $\Theta$ 


\section{Palavras-chave}

- período pós-parto

- útero

- ultrassonografia complicada, considerando a influência da paridade, tipo de parto, amamentação e peso ao nascer sobre a involução uterina.

Métodos Noventa e uma pacientes foram submetidas a exame ultrassonográfico nos dias 1 (D1), 2 (D2) e 7 (D7) do puerpério. Os diâmetros uterinos longitudinal, anteroposterior e transversal foram medidos, e o volume uterino foi calculado pela fórmula: diâmetro longitudinal (DL) X diâmetro anteroposterior (DAP) X diâmetro transverso (DT) $\times 0,45$. A espessura e comprimento da cavidade uterina também foram medidos.

Resultados O volume uterino e o DL, DAP e DT diminuíram $44,8 \%, 20,9 \%, 11.8 \%$ e $20,0 \%$ respectivamente no D7. A espessura da cavidade uterina reduziu em $23 \%$, e o comprimento da cavidade foi reduzido em $27,2 \%$ no D7. A involução uterina se correlacionou inversamente com a paridade quando o dia do puerpério não foi levado em conta $(p=0,01)$. Uma diferença significativa foi encontrada em D2, quando se verificou que o útero tinha um volume menor no grupo submetido a cesariana em comparação com o parto vaginal $(p=0,04)$. O peso ao nascer elevado e amamentação apresentaram relação estatisticamente significativa com a involução uterina $(p \leq 0,01$ e $p=0,04)$.

Conclusão A avaliação ultrassonográfica do útero no puerpério precoce deve considerar o peso ao nascer, a amamentação e a paridade, assim como a via de parto no D2, para a identificação de anormalidades relacionadas à involução uterina.

\section{Introduction}

During the postpartum period, the uterus, which weighs over $1 \mathrm{~kg}$ immediately after parturition, undergoes a physiological involution and returns to the non-pregnant condition. ${ }^{1}$ The process of involution, which is one of the main characteristics of the postpartum period, may be affected in pathological conditions such as uterine infection and hemorrhage. ${ }^{1,2}$ Both are main causes of maternal death worldwide; therefore, a correct diagnosis is of paramount importance., ${ }^{1,2}$

The uterine involution has been previously evaluated with respect to the palpation of the uterine height, which can be difficult in obese women or in those with uterine myoma. ${ }^{1}$ The uterus was one of the first organs to be examined by ultrasonography when ultrasound was introduced into the clinical practice by Donald and his collaborators. ${ }^{2}$ The high-resolution ultrasound equipment that is currently available increases the role of ultrasonography in assessing the normal and abnormal ${ }^{3}$ puerperal dynamics. Ultrasonography is a non-invasive, lowcost technique that is well accepted by patients. ${ }^{2}$

There is no consensus in the literature regarding the influence of some factors, such as parity, ${ }^{4-10}$ breastfeeding $^{5-8,10}$ and birth weight, ${ }^{5,6,8,10}$ on uterine involution. It is important to know the normal ultrasonographic involution of the uterus during the postpartum period to improve our ability to distinguish the pathological from the normal puerperium and thereby avoid unnecessary invasive procedures. Furthermore, the knowledge obtained from ultrasonographic examinations can help us better understand the physiology of the postpartum period. The postpartum period has been arbitrarily divided into the immediate puerperium, or the first 24 hours after parturition; the early puerperium, which extends until the first week postpartum; and the remote puerperium, which includes the period of time required for involution of the genital organs and return of menses, usually $\sim 6$ weeks.

The aim of this study was to describe the changes in the uterine dimensions using ultrasound in the early puerperium following cesarean section or vaginal birth among women delivering term singleton infants who experienced an uncomplicated postpartum period. A secondary objective was to assess the influence of parity, mode of delivery, breastfeeding and birth weight on uterine involution according to the time at which it was assessed.

\section{Methods}

Ninety-one puerperal women who delivered singletons at term at Hospital Universitário Antonio Pedro and Maternidade Municipal Alexander Fleming in the city of Rio de Janeiro, Brazil, were invited to participate. The Committee of Ethics in Research from Universidade Federal Fluminense approved this study. All the subjects received and signed the free and informed consent form. The exclusion criteria were the presence of postpartum infections (surgical wound or endometritis) or placental remains.

The patients underwent pelvic (transvaginal and transabdominal) ultrasound evaluations on days 1 (D1), 2 (D2) and 7 (D7) of the postpartum period. The ultrasound equipment used was Sonoace 8000 EX prime (Medison, Seoul, Seoul, South Korea) with a $3.5-\mathrm{MHz}$ convex transducer. The examinations included the assessment of: the longitudinal, anteroposterior and transverse uterine diameters; the 
uterine volume (by the formula: longitudinal diameter (LD)X anteroposterior diameter (APD) X transverse diameter (TD) X 0.45 ); and the thickness and length of the uterine cavity. The patients were asked whether they were breastfeeding. Birth weight, mode of delivery and parity were obtained from the obstetric records.

All of the examinations were performed by a single researcher directly involved in the project. Data were analyzed with the statistical analysis program S-Plus 8.0 (Solution Metrics, Sydney, Australia). The studied parameters underwent a descriptive analysis, and the results were expressed as the mean and standard deviation (SD). Parametric and nonparametric mean comparison tests were used (analysis of variance [ANOVA] and Spearman's rank correlation coefficient).

The authors declare no conflict of interest.

\section{Results}

Ninety-one puerperal women underwent pelvic ultrasonographic examinations on D1 and D2, and 57 women also had an exam on D7 (total of 239 assessments). The mean age was 24 years (range 13-41 years). The most prevalent self-reported skin color among the patients was racially mixed ( $n=43$ ), followed by women who reported being white ( $n=26)$, and the less prevalent, who reported being black $(n=22)$. Thirty-seven women were primiparous, 24 were secundiparous, and 30 had had 3 or more parturitions. The average number of children was 2.3. Fifty-four deliveries were vaginal, and 37 deliveries were by cesarean section. The average birth weight was 3,184 g (range 2,125-4,320 g); 20 infants weighed more than $3,500 \mathrm{~g}$, and only 10 weighed less than $1,500 \mathrm{~g}$. Most puerperal women $(n=80)$ reported breastfeeding.

-Fig. 1 illustrates the variations in the uterine volume and diameter for each day of the postpartum period evaluated; ANOVA was conducted, and a boxplot is displayed. a) In the first postpartum week, the mean uterine volume was decreased by $44.8 \%$, corresponding to a reduction from $840 \mathrm{~cm}^{3}$ on D1 to $463 \mathrm{~cm}^{3}$ on D7. From D1 to D2, the mean uterine volume decreased less (from 840 to $717 \mathrm{~cm}^{3}$, corresponding to $14.6 \%$ ). b) The mean uterine longitudinal diameter was $18.3 \mathrm{~cm}$ on D1. It decreased by $3.9 \%$ on D2 to an average of $17.6 \mathrm{~cm}$, and it decreased by $20.9 \%$ on D7 to an
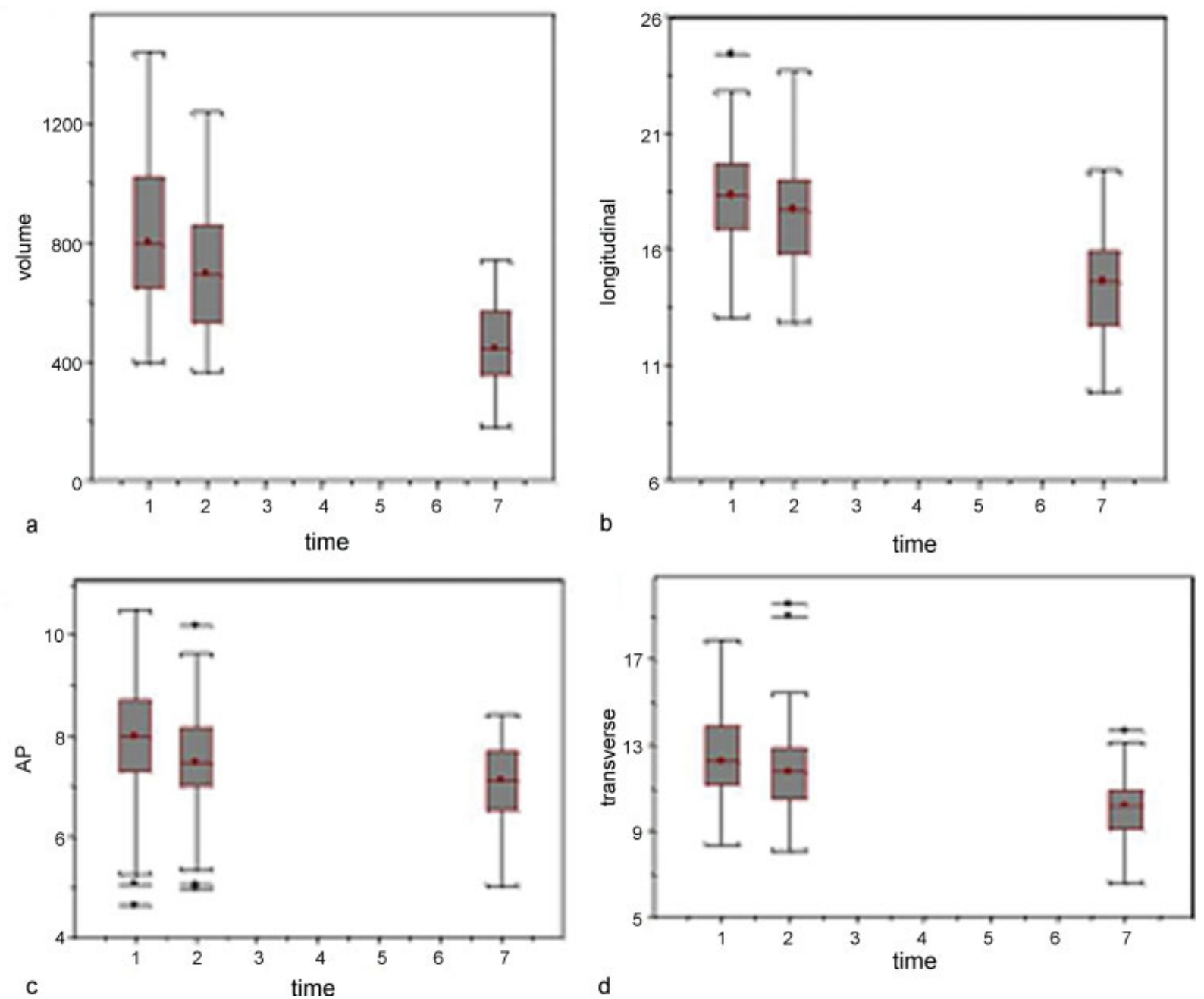

Fig. 1 Boxplot of the observed values of the uterine dimensions on D1, D2 and D7: (a) uterine volume ( $\mathrm{cm}^{3}$ ); (b) longitudinal diameter (cm); (c) anteroposterior diameter $(\mathrm{cm})$; and (d) transverse diameter $(\mathrm{cm})$. 
average of $14.5 \mathrm{~cm}$. c) The uterine anteroposterior diameter decreased by $5.5 \%$ from D1 to D2, corresponding to an average change from 8.0 to $7.6 \mathrm{~cm}$. Reductions in size were maintained until D7, when the average was $7.1 \mathrm{~cm}$, corresponding to a reduction of $11.8 \%$. d) The uterus transverse diameter was $12.5 \mathrm{~cm}$ on D1. The average diameter was $11.8 \mathrm{~cm}$ on $\mathrm{D} 2$, which represented a decrease of $5.1 \%$, and the average was $10.1 \mathrm{~cm}$ on $\mathrm{D} 7$, which represented a decrease of $20.0 \%$.

The variations in the dimensions of the thickness and length of the uterine cavity during the study period were also verified. a) In the first week postpartum, the uterine cavity thickness decreased by $23 \%$; the average thickness decreased from $0.7 \mathrm{~cm}$ on D1 to $0.57 \mathrm{~cm}$ on D7. b) The uterine cavity length decreased by $27.2 \%$ during the same period; the average length decreased from $13.4 \mathrm{~cm}$ on D1 to $9.7 \mathrm{~cm}$ on D7.

When the factors that could influence the uterine involution were analyzed, it was found that parity, regardless of the postpartum day, was significantly correlated $(p=0.01)$ with uterine involution. Spearman's rank correlation coefficient confirmed a direct correlation between parity and uterine volume, although it was weak $(r=0.16)$ (-Fig. 2). However, no significant differences were found from the parity analyses when the time from birth was taken into account. The significance of the influence of parity on the uterine volume, regardless of time, resulted in an analysis of the overlapping regions that can be observed in -Fig. 3. When the values obtained on D1, D2 and D7 are plotted on this graph, it is possible to observe a tendency to form an ascendant line, parallel to the axis of parity, on D1, D2 and D7; when analyzed separately, no such relation was found. Positive correlations were found among birth weight $(\mathrm{p} \leq 0.01)$, breastfeeding $(p=0.04)$ and uterine volume at all of the periods studied.

- Table 1 presents the analysis of the effect of the delivery mode on uterine involution according to time. Vaginal deliveries and deliveries by cesarean section yielded similar uterine volumes. The only significant difference occurred on D2, when the uterine volume was found to be smaller in women who underwent delivery by cesarean section $(p=0.044)$.

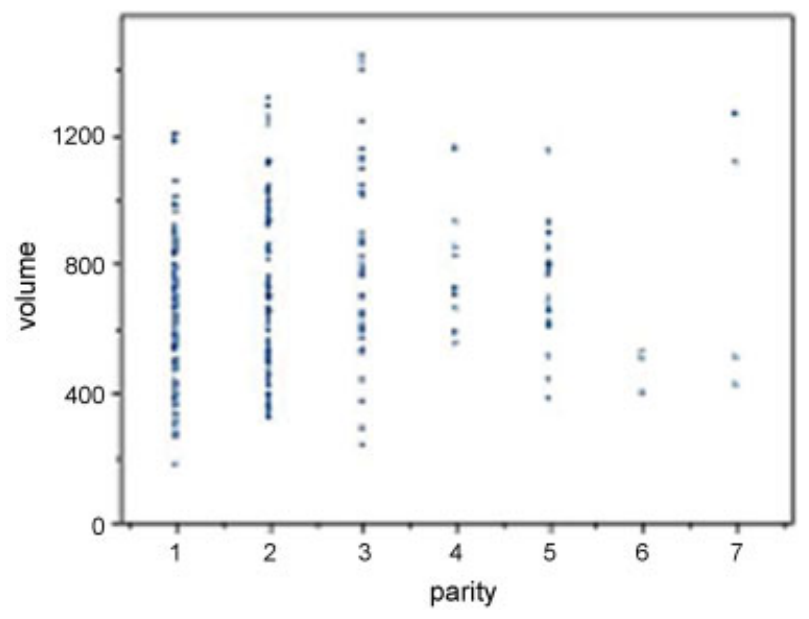

Fig. 2 Correlation between parity and uterine volume $\left(\mathrm{cm}^{3}\right)$, without taking the examination time into consideration (ANOVA: $p=0.01$; Spearman's rank correlation coefficient: $r=0.16)$.

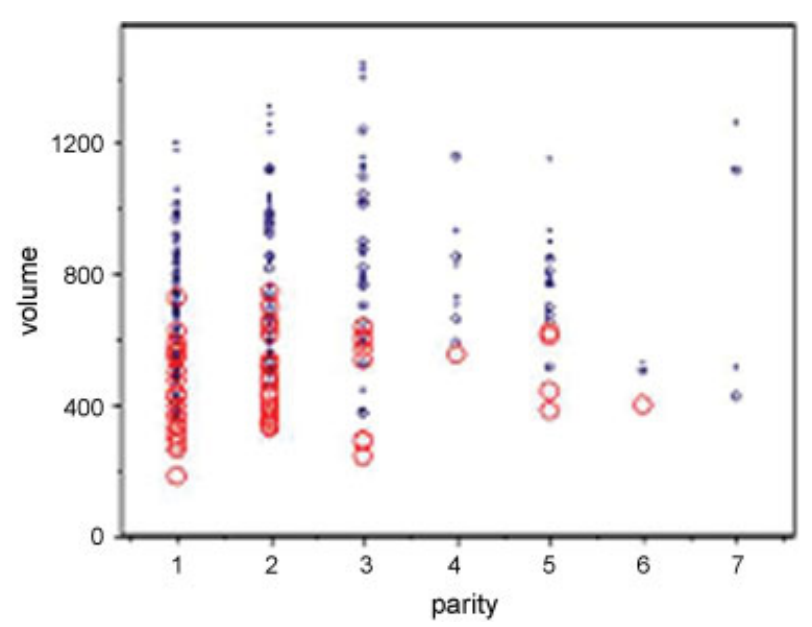

Fig. 3 Correlation between parity and uterine volume $\left(\mathrm{cm}^{3}\right)$ at overlapping times (D1, D2 and D7). D1 is expressed as small blue circles, D2 is expressed as medium blue circles, and D3 is expressed as red circles.

\section{Discussion}

Since the introduction of ultrasonography into the obstetric practice, ${ }^{2}$ performing non-invasive investigations of the uterus was made possible. ${ }^{5}$ Several authors have examined the uterus by ultrasonography after vaginal births. Sokol et al $^{11}$ performed ultrasound exams 48 hours after vaginal birth. Edwards and Ellwood ${ }^{12}$ evaluated 40 patients on postpartum days 7, 14 and 21, and Al-Bdour et $\mathrm{al}^{8}$ evaluated women on postpartum days 1, 7, 14, 28 and 56. Defoort et $\mathrm{al}^{7}$ performed ultrasound examinations in the first 24 hours after vaginal birth, and found a significant correlation between parity and uterine involution. Many authors evaluated uterus involution after birth using a three-dimensional (3D) ultrasound. Belachew et $\mathrm{al}^{13}$ studied using the transabdominal ultrasound on days 1, 7 and 14, and the transvaginal ultrasound on days 28 and 56 postpartum in 63 women after spontaneous delivery. The median uterine volume decreased from $756 \mathrm{~cm}^{3}$ on day 1 postpartum to $440 \mathrm{~cm}^{3}$ on day 7 . The mean uterine volume was decreased by $41.8 \%$, and these results are similar to our data. Wataganara et $\mathrm{al}^{14}$ found a high correlation between two-dimensional (2D) and 3D ultrasound estimations of the uterine volume.

When we analyzed the influence of parity on the uterine volume, we found a significant direct correlation $(p=0.01)$,

Table 1 Effect of delivery mode on uterine involution according to day (Student's t test)

\begin{tabular}{|l|l|l|l|l|}
\hline $\mathbf{n}$ & Day & $\begin{array}{l}\text { Vaginal deliveries } \\
\text { (mean uterine } \\
\text { volume) }\end{array}$ & $\begin{array}{l}\text { Cesarean section } \\
\text { (mean uterine } \\
\text { volume) }\end{array}$ & $p$ \\
\hline 91 & D1 & 852.6 & 814.1 & 0.477 \\
\hline 91 & D2 & 754.4 & 663.0 & 0.044 \\
\hline 57 & D7 & 467.8 & 456.3 & 0.754 \\
\hline
\end{tabular}


regardless of the examination time. When the analysis of the effect of parity on the uterine volume was performed according to the examination time (D1, D2, and D7), no significant correlation was found at any of the studied times, which is similar to the results from the literature. Belachew et al ${ }^{13}$ also found no significant difference (D1 and D7) using the VOCAL imaging program (3D ultrasound technology). When we disregard the influence of the examination time in the analysis, an increase in parity is correlated with larger uterine volumes, unlike when we evaluate each period of time separately. Parity was not significantly correlated with the uterine volume. Wataganara et al $^{14}$ considered the uterinevolume to be independent of parity

Diniz et $\mathrm{al}^{15}$ performed abdominal ultrasound evaluations during the first 48 hours after childbirth. The mean volume of the uterus was greater than our results when we compare with D2.

The mode of delivery was analyzed by Negishi et al, ${ }^{16}$ who evaluated 319 puerperal women after vaginal birth and 72 after cesarean section, and found larger uterine volumes after cesarean section. However, the results were not statistically significant. Koskas et $\mathrm{al}^{17}$ postulated that discrepancies between uterine measurements can occur due to the differences among the surgical techniques and the doses of oxytocin given following a cesarean section, which can be different than those given to patients following a vaginal birth. Bae et al $^{18}$ evaluated uterine involution 2 and 6 weeks postpartum. They showed differences in relation to delivery mode and gestational age at delivery.

When evaluating birth weight, we observed a significant direct correlation with the uterine volume $(p<0.01)$, regardless of the examination time. Buisson et al, ${ }^{19}$ Wachsberg et $\mathrm{al}^{10}{ }^{10}$ Mulic-Lutvica et $\mathrm{al}^{5}$ and Al-Bdour et $\mathrm{al}^{8}$ did not find this correlation. Rodeck and Newton ${ }^{6}$ found a significant correlation between the birth weight and the uterine cavity length on the first postpartum day, but only among secundiparous women.

A significant direct correlation was found between breastfeeding and the uterine volume $(p=0.04)$, regardless of time, although the number of puerperal women who reported exclusive breastfeeding (80) was much higher than the number of women who reported other breastfeeding practices (11), which prevented a meaningful statistical analysis. Negishi et al $^{16}$ analyzed non-exclusive breastfeeding. They did not find significant differences in the size of the uterus one month after vaginal birth among women with breastfeeding rates of $80 \%$ per day (infants required complementary feeding with non-breast milk sources until $20 \%$ of daily energy expenditure) and in women with breastfeeding rates of $20 \%$ per day. However, the longitudinal and anteroposterior diameters 3 months after delivery in women with breastfeeding rates of $80 \%$ were lower than those in women with breastfeeding rates of $20 \%$. Rodeck and Newton, ${ }^{6}$ Defoort et al, ${ }^{7}$ Buisson et al, ${ }^{19}$ Wachsberg et al, ${ }^{10}$ Mulic-Lutvica et $a{ }^{5},{ }^{5}$ Sokol et $\mathrm{al}^{11}$ and Wataganara et $\mathrm{al}^{14}$ considered the uterine volume to be independent of breastfeeding.

The major difficulty in conducting this study was the limited number of measurements made on D7. Long distances between the homes of some women and the place where the examinations were performed, as well as the demands of childcare, were the main causes of the nonattendance on the last day of examinations.

Although there is no consensus in the literature regarding the influence of factors such as parity, breastfeeding and birth weight on the process of uterine involution, knowledge of the normal ultrasound changes of the uterus during the postpartum period is a prerequisite for the ultrasound diagnosis of pathological conditions. Ultrasound is a low-cost and painless diagnostic tool that is easily accessible to the population. It may provide a best quality of health assistance for women if it is available to clarify many puerperal abnormalities. ${ }^{18}$ Ideally, each obstetrics service would have its own reference curve with values corresponding to its own patients. Medical care for pregnant women does not end with parturition, as care during the puerperium represents a good indicator of the life and health quality of a population.

\section{References}

1 Beazley JM, Underhill RA. Fallacy of the fundal height. BMJ 1970;4 (5732):404-406

2 Donald I, MacVicar J, Brown TG. Investigation of abdominal masses by pulsed ultrasound. Lancet 1958;1(7032):1188-1195

3 Almeida CM. Curva da involução uterina no puerpério normal por ultrassonografia [dissertação]. Campinas: Universidade Estadual de Campinas; 2002

4 Mauad Filho F, Beduschi AF, Albergue R, et al. [Ultrasonographic evaluation of uterine volume variations]. Rev Bras Ginecol Obstet 2001;23(03):175-179 Portuguese.

5 Mulic-Lutvica A, Bekuretsion M, Bakos O, Axelsson O. Ultrasonic evaluation of the uterus and uterine cavity after normal, vaginal delivery. Ultrasound Obstet Gynecol 2001;18(05):491-498

6 Rodeck CH, Newton JR. Study of the uterine cavity by ultrasound in the early puerperium. Br J Obstet Gynaecol 1976;83(10): 795-801

7 Defoort P, Benijts G, Thiery M, Martens G. Ultrasound assessment of puerperal uterine involution. Eur J Obstet Gynecol Reprod Biol 1978;8(02):95-97

8 Al-Bdour ANA, Akasheh HF, Al-Husban NA. Ultrasonography of the uterus after normal vaginal delivery. Saudi Med J 2004; 25(01):41-44

9 Lee CY, Madrazo B, Drukker BH. Ultrasonic evaluation of the postpartum uterus in the management of postpartum bleeding. Obstet Gynecol 1981;58(02):227-232

10 Wachsberg RH, Kurtz AB, Levine CD, Solomon P, Wapner RJ. Realtime ultrasonographic analysis of the normal postpartum uterus: technique, variability, and measurements. J Ultrasound Med 1994;13(03):215-221

11 Sokol ER, Casele H, Haney EI. Ultrasound examination of the postpartum uterus: what is normal? J Matern Fetal Neonatal Med 2004;15(02):95-99

12 Edwards A, Ellwood DA. Ultrasonographic evaluation of the postpartum uterus. Ultrasound Obstet Gynecol 2000;16(07): 640-643

13 Belachew J, Axelsson O, Mulic-Lutvica A, Eurenius K. Longitudinal study of the uterine body and cavity with three-dimensional ultrasonography in the puerperium. Acta Obstet Gynecol Scand 2012;91(10):1184-1190

14 Wataganara T, Phithakwatchara N, Komoltri C, Tantisirin P, Pooliam J, Titapant V. Functional three-dimensional sonographic 
154 Ultrasonographic Evaluation of Uterine Involution in the Early Puerperium Kristoschek et al.

study of the postpartum uterus. J Matern Fetal Neonatal Med 2015;28(18):2221-2227

15 Diniz CP, Araujo Júnior E, Lima MM, Guazelli CA, Moron AF. Ultrasound and Doppler assessment of uterus during puerperium after normal delivery. J Matern Fetal Neonatal Med 2014;27(18): 1905-1911

16 Negishi H, Kishida T, Yamada H, Hirayama E, Mikuni M, Fujimoto S. Changes in uterine size after vaginal delivery and cesarean section determined by vaginal sonography in the puerperium. Arch Gynecol Obstet 1999;263(1-2):13-16
17 Koskas M, Nizard J, Salomon LJ, Ville Y. Abdominal and pelvic ultrasound findings within 24 hours following uneventful Cesarean section. Ultrasound Obstet Gynecol 2008;32(04):520-526

18 Bae HS, Ahn KH, Oh MJ, Kim HJ, Hong SC. Postpartum uterine involution: sonographic changes in the endometrium between 2 and 6 weeks postpartum related to delivery mode and gestational age at delivery. Ultrasound Obstet Gynecol 2012;39(06):727-728

19 Buisson P, Tomikowski J, Santarelli J, Kapitaniak B. Clinical and ultrasonographic study of uterine involution in postpartum physiology. Rev Fr Gynecol Obstet 1993;88(01):12-18 